\title{
KONVERSI BANK RIAU KEPRI MENJADI BANK SYARIAH DALAM PEREKONOMIAN MASYARAKAT DAN UMAT ISLAM DI PROPINSI RIAU
}

\author{
Nurhadi \\ Sekolah Tinggi Agama Islam (STAI) Al-Azhar Pekanbaru \\ alhadijurnal@gmail.com
}

\begin{abstract}
Riau public awareness of a usury-free bank has shown the positive conversion of Riau BUMD Bank Riau Riau Islands into Sbaria-based Banking. Riau Kepr Bank can be converted into an Islamic bank by not breaking the existing rules, just the process and mechanism that must be followed in accordance with the procedures and rules set by the Financial Services Authority. Bank Riau Kepri if converted will become a Sharia Bank, has the opportunity to become one of the 10 largest Islamic banks in Indonesia if analyzed from the side of Riau Riau Regional BUMD assets, but still survive in conventional banks, then only in the order of 80 of the 118 banks in Indonesia, clearly it will be increasingly difficult to compete amid the ASEAN economic market and the onslanght of global banks scrambling to enter the Indonesian market. Bumi Lancang Kuning Melayu Riau and Kepri are synonymous with Islam, even though they have lived in neighboring tribes for a long time, but the law that has always been used long ago is Islamic law based on the Book of Allah and the Sunnah of the Prophet and all components of society can live peacefully and peacefully. Bank Riau Kepri was converted into a sharia bank. so it would eliminate the doubt (besitation) in the bearts of employees working in conventional banks especially with the existence of the MUI Fatwa No. 1 of 2004 stating bank interest included Haram and Riba.
\end{abstract}

Keywords: Conversion, Bank Riau Kepri, Islamic Bank, Recruitment Society

\begin{abstract}
Abstrak : Kesadaran masyarakat Riau terhadap bank bebas riba telah menunjukkan sikap positif dari penukaran Riau BUMD Bank Riau Kepri menjadi Perbankan berbasis Syariah. Bank Riau Kepri dapat diubah menjadi bank Islam dengan tidak melanggar peraturan yang ada, hanya proses dan mekanisme yang harus diikuti sesuai dengan prosedur dan peraturan yang ditetapkan oleh Otoritas Layanan Keuangan. Bank Riau Kepri jika ditukar menjadi Bank Syariah, berpeluang menjadi salah satu dari 10 bank syariah terbesar di Indonesia jika dianalisis dari perspektif aset BUMD Kepulauan Riau Riau, sebaliknya masih bertahan di bank konvensional, jadi hanya dalam urutan 80 dari 118 bank yang ada di Indonesia, jelas akan semakin sukar untuk bersaing di tengah-tengah pasar ekonomi ASEAN dan serangan bank-bank global yang bergegas memasuki pasar Indonesia. Bumi Lancang Kuning Melayu Riau dan Kepulauan Riau identik dengan Islam, walaupun mereka telah lama tinggal sebagai jiran dengan pelbagai suku, tetapi undang-undang yang selalu digunakan adalah undangundang Islam yang bergantung kepada Kitab Allah dan sunnah Rasulullah dan semua komponen masyarakat dapat hidup dalam kedamaian dan kedamaian. Bank Riau Kepri diubah menjadi bank Islam, ia akan menghilangkan syak (ragu-ragu) di hati para pekerja yang bekerja di bank konvensional, terutama dengan adanya MUI Fatwa No. 1 tahun 2004 yang menyatakan kepentingan bank termasuk Haram dan Riba.
\end{abstract}

Kata Kunci: Konversi, Bank Riau Kepri, Bank Syariah, Perekonomia Umat

Islamika : Jurnal Keislaman dan Ilmu Pendidikan

Volume 2, Nomor 2, Juli 2020; 276-297

https:// ejournal.stitpn.ac.id/index.php/islamika 


\section{PENDAHULUAN}

Pemegang Peto Otoritas Jasa Keuangan (OJK) Provinsi Riau mengingatkan pemegang saham Bank Riau Kepri (BRK) untuk melakukan studi dan survei mendalam. Ini perlu dilakukan jika pemegang saham ingin mengubah Bank Pembangunan Daerah menjadi syariah. Satu hal yang harus dipahami adalah bahwa setelah konversi ke bank syariah tidak lagi dapat dikembalikan ke konvensional, kata Kepala OJK Yusri Riau di Pekanbaru, Yusri menjelaskan rencana konversi BRK harus dipersiapkan dengan sangat baik. Hal utama yang harus dilakukan oleh bank regional selain banyak persyaratan adalah studi kualitas dan survei tentang preferensi pelanggan mereka dan masyarakat Riau sendiri. ${ }^{1}$

Menurut Yusri, studi dan survei harus dapat mencerminkan respons pelanggan BRK dan masyarakat Riau. Kemudian rencana konversi adalah seberapa besar dukungan dan keinginan pelanggan dan masyarakat Riau, katanya. Selain itu, hasil studi dan survei harus dapat meyakinkan pemangku kepentingan dan khususnya Otoritas Jasa Keuangan bahwa BRK Syariah akan tumbuh dan berkembang lebih baik daripada ketika konvensional. ${ }^{2}$

Secara teknis, ada banyak hal yang harus dipersiapkan BRK untuk dikonversi menjadi syariah, termasuk kesiapan karyawan BRK, teknologi informasi (TI), Standar Operasional Produk (SOP) dan, yang paling penting, membutuhkan waktu yang cukup untuk persiapan, tambahnya. Sebelumnya diprediksi bahwa Bank Riau Riau akan dikonversi menjadi bank syariah. Konversi dari bank konvensional ke Syariah adalah persetujuan pemegang saham dalam rapat umum pemegang saham (RUPS) pada akhir 2018. Sekretaris Provinsi Riau (Sekdaprov) Ahmad Hijazi mengatakan bahwa dengan perjanjian tersebut, BRK diminta untuk melakukan studi untuk konversi dari konvensional ke syariah. Yang jelas, BRK diminta membuat studi tentang sistem syariah yang benar-benar bisa diterapkan di BRK, kata Ahmad Hijazi. ${ }^{3}$

1Republika. "Bank Riau Kepri Ingin Konversi ke Syariah, Ini Saran OJK”. m.republika.co.id. (26-012019). https://m.republika.co.id/berita/ekonomi/syariah-ekonomi/19/01/26/plxfau383-bank-riaukepri-ingin-konversi-ke-syariah-ini-saran-ojk, diakses 21 Juli 2019.

Ibid.

${ }^{3}$ Ibid. 
Rencana konversi ke syariah, kata Ahmad Hijazi, juga mendapat tanggapan positif dari pemegang saham. Namun sebelum penerapan BRK Syariah, katanya, studi dilakukan terlebih dahulu. Salah satunya adalah survei tanggapan masyarakat terkait dengan rencana tersebut. Studi ini sebenarnya ingin melihat sejauh mana indikator keberpihakan masyarakat. Nanti akan diukur di sana, mungkin potensi dana masyarakat dicurahkan, katanya. Dia menambahkan, konversi itu disarankan mengingat Riau adalah wilayah Melayu, yang penuh dengan Islam. Riau adalah budaya Melayu. Bahasa Melayu identik dengan Islam. Islam identik dengan syariah. Termasuk memahami iman kita tentang riba, katanya. ${ }^{4}$

PT Bank Pembangunan Daerah Riau Kepri (Bank Riau Kepri) terus berencana untuk mengkonversi ke bank komersial syariah dalam dua hingga tiga tahun ke depan. Direktur Bank Riau Kepri Irvandi Gustari mengatakan, perusahaan telah menyelesaikan studi awal untuk melakukan konversi seperti yang diamanatkan oleh pemegang saham pada rapat umum pemegang saham (RUPS) pada tahun 2018. Kami telah melakukan penilaian konversi ke bank syariah . "Rencana kami untuk RUPS berikutnya pada bulan April akan dilakukan memalu, meratifikasi penelitian dan melanjutkan konversi," katanya kepada Bisnis baru-baru ini. ${ }^{5}$

Rencana untuk mengubah model bisnis bank dari bank komersial sebelumnya menjadi syariah, kata Irvandi, karena pemegang saham melihat potensi pengembangan bisnis di segmen tersebut. Hal ini terkait dengan latar belakang masyarakat di Riau dan Kepulauan Riau yang cukup kental dengan budaya Islam. Berkaca pada pengalaman beberapa bank daerah yang melakukan konversi ke bank umum syariah seperti di NTB dan Aceh, menurut Irvandi, proses persiapan diperkirakan akan memakan waktu dua hingga tiga tahun ke depan. ${ }^{6}$

Selama masa transisi, perusahaan akan menyiapkan sumber daya manusia, produk, mengembangkan SOP dan jaringan infrastruktur teknologi. Selain itu, perusahaan juga perlu menyiapkan lisensi, termasuk Otoritas Jasa Keuangan dan

${ }^{4}$ Ibid.

${ }^{5}$ Bisnis Com. "Bank Riau Kepri Segera Konversi Jadi Bank Syariah". finansial.bisnis.com. (2103- 2019). https:// finansial.bisnis.com/read/20190321/90/902583/bank-riau-kepri-segera-konversijadi-bank-syariah, diakses 21 Juli 2019.

Ibid. 
peraturan daerah terkait. Perusahaan juga akan mensurvei pelanggan dan bisnis di Riau dan Kepulauan Riau dan memerlukan setidaknya 50\% dukungan untuk beroperasi dalam bentuk bank syariah. ${ }^{7}$

Jika NTB dulu 2 tahun, kami perkirakan akan lebih lama karena ukuran Bank Riau Riau lebih besar, terutama karena kami beroperasi di dua provinsi," katanya. Jika sudah terealisasi, lanjut Irvandi, bank umum syariah Kepri Riau masih akan masuk dalam kategori Bank Bisnis Komersial (BUKU) II dengan modal Rp1 triliun-Rp5 triliun. Sedangkan untuk bisnis pembiayaan yang dilakukan oleh perusahaan diperkirakan masih tidak jauh berbeda, yaitu mayoritas di segmen konsumen. ${ }^{8}$

Kami tetap BUKU II tapi kami akan menjadi bank syariah terbesar nomor 5 dengan aset sekarang Rp 27 triliun sedangkan Bank Aceh akan menjadi nomor 6 dengan aset saat ini Rp 23 triliun, paparnya. Pada perkembangan lain, Bank Riau Kepri juga masih melanjutkan rencana penambahan permodalan dari pemegang saham pada tahun ini. Sepanjang 2018 lalu, pemegang saham sepakat menambah Rp 27 miliar permodalan. Namun dari tujuh kabupaten / kota yang ada, baru dua yang telah merampungkan perda sehingga penambahan modal yang terealisasi masih berkisar Rp 5 miliar. Hingga September 2018, jumlah modal inti tier 1 perseroan tercatat sebesar Rp 2,67 triliun. Tahun ini kayaknya kalau Perda keluar dari Pemprov dan uangnya ada, tambahan modalnya bisa mencapai Rp 350 miliar, paparnya.

Ketika kami menjelajahi data pada prinsipnya, ada persamaan bisnis inti. Bank Aceh, Bank NTB, Bank Nagari dan Bank Riau Kepri. Bank Pembangunan Daerah yang dimiliki oleh Pemerintah Daerah. Bank Pembangunan Daerah didirikan dengan tujuan untuk memberdayakan ekonomi daerah, mendorong pertumbuhan UMKM dan dari keuntungan mereka bersama sebagai salah satu sumber pendapatan daerah (PAD). ${ }^{10}$

${ }^{7}$ Bisnis Com. "Spin Off Unit Usaha Syariah: Bank Riau Kepri Optimistis Mulus". kalimantan.bisnis.com. (19-02-2018). https://kalimantan.bisnis.com/read/20180219/445/739954/spin-off-unit-usaha-syariah-bank-riaukepri-optimistis-mulus, diakses 25 Juli 2019.

${ }^{8} \mathrm{Ibid}$.

${ }^{9}$ Ibid.

${ }^{10}$ Direktur Bid. Syariah PT. Bank Riau Kepri. "Bank Riau Kepri Menjadi Bank Syariah, Suatu Wacana”. www.halloriau.com. (30-06-2016). http://www.halloriau.com/read-ekonomi-81868-2016-06-30-bankriau-kepri-menjadi-bank-syariah-suatu-wacana.html, diakses 21 Juli 2019. 
PT Bank Pembangunan Daerah Riau Kepri atau Bank Riau Kepri (BRK) terus berencana untuk mengkonversi ke bank umum syariah dalam dua hingga tiga tahun ke depan. Sebagai lembaga pengawas, Otoritas Jasa Keuangan (OJK) melakukan pengawasan ketat. Seperti diketahui Perusahaan telah menyelesaikan studi pendahuluan untuk melakukan konversi seperti yang diamanatkan oleh pemegang saham pada Rapat Umum Pemegang Saham 2018 (RUPS) terakhir. ${ }^{11}$

Rencana untuk mengubah model bisnis bank dari bank komersial sebelumnya menjadi syariah karena pemegang saham melihat potensi pengembangan bisnis di segmen tersebut. Hal ini terkait dengan latar belakang masyarakat di Riau dan Kepulauan Riau yang cukup kental dengan budaya Islam. Rencana tersebut terus dipantau oleh otoritas jasa keuangan dengan menyoroti kesiapan BRK untuk konversi ke bank syariah, masalah sumber daya manusia dan teknologi di BKR menjadi perhatian khusus bagi badan pengawas dan audit jasa keuangan OJK, kata OJK Provinsi Riau. kepala Yusri pada hari Selasa. ${ }^{12}$

Dia mengatakan masalah SDM, semua karyawan BRK harus diberikan pelatihan tentang perbankan syariah. Berkaca pada pengalaman beberapa bank daerah yang melakukan konversi ke bank umum syariah seperti di NTB dan Aceh, proses persiapannya memakan waktu yang cukup lama, katanya. Yusri mengatakan selama masa transisi, perusahaan diharuskan menyiapkan sumber daya manusia, produk, menyusun SOP dan jaringan infrastruktur teknologi. Selain itu, perusahaan juga perlu menyiapkan perizinan, termasuk otoritas jasa keuangan yang relevan dan peraturan lokal, di samping dukungan untuk beroperasi dalam bentuk bank syariah setidaknya 50 persen dari pelanggan, ia menekankan. ${ }^{13}$

Dalam Rapat Umum Pemegang Saham Luar Biasa (RUPS-LB) Bank Riau Kepri (BRK) yang digelar Senin (22/4/2019) malam, pemegang saham sepakat mengkonversi Bank Riau Kepri menjadi Bank Syariah. Hal ini menjadi sorotan publik dan mendapat respon dari akademisi Riau. Kita tentunya mendukung apa yang sudah

\footnotetext{
${ }^{11}$ Radio Republik Indonesia. "OJK Awasi Ketat Proses Konversi BRK Menjadi Bank Syariab”. rri.co.id. (23-07-2019). bttp:// rri.co.id/pekanbaru/post/berita/697519/ekonomi/ojk_awasi_ketat_proses_konversi_brk_menjadi_bank_ syariah.btml, diakses 23 Juli 2019.

${ }^{12}$ Ibid.

${ }^{13}$ Ibid.
} 
menjadi keputusan para pemegang saham yang sudah merealisasikan wacana Gubernur untuk melakukan konversi BRK menjadi bank syariah. Apalagi memang Pemegang saham terbesar adalah Pemprov Riau dalam hal ini Gubernur, tentu ini harus diperhitungkan dan didukung, ujar Akademisi Riau Saiman Pakpahan kepada Cakaplah.Com. ${ }^{14}$

Dosen Fisipol Universitas Riau ini mengatakan pihaknya mendorong tim konversi BRK Syariah bekerja dengan baik dan sesegera mungkin melaporkan progresnya dari waktu ke waktu kepada gubernur.. Kepada Gubernur bisa menjadi rasionalitas akademik terhadap kerja besar Konversi BRK ini, cakapnya. Disampaikan oleh Kandidat Doktor Ilmu Sosial UNPAD ini, wacana konversi Bank Syariah memang tak hanya di BRK tapi sudah ada di bank lain seperti Bank Nagari, Bank DKI, Bank Lampung dan BPD lainnya. ${ }^{15}$

Secara ekonomi, prinsip perbankan syariah ini dianggap sebagai mekanisme perbankan yang akomodatif terhadap roda perekonomian Indonesia dan Riau Kepri khususnya yang mayoritas Islam. Prinsip Ekonomi Syariah yang adil itulah yang membuat gubernur ingin cepat-cepat melakukan konversi. Jadi kenapa ini diterapkan? Agar berkah dan terhindar dari riba yang memang banyak berkembang di bank-bank konvensional, tegasnya. Sementara itu, terkait kekosongan dua jabatan di BRK yakni Direktur Utama dan Komisaris Utama, pria yang sebelumnya juga masuk dalam tim transisi pasangan gubernur dan wakil gubernur Riau Syamsuar-Edy Natar ini menilai kondisi seperti ini tidak akan terlalu mengganggu jalannya roda organisasi di BRK. ${ }^{16}$

BRK inikan organisasi yang usianya sudah lama, artinya sudah ada sistem dan prosedur baku yang terbentuk. Jadi 2 Direktur lama dan 1 Direktur baru yang ada saat ini pasti bisa membawa organisasi perbankan BRK itu pada tujuan yang diharapkan, terangnya. Namun tentu saja, terhadap kekosongan itu pihaknya berharap kepada Gubernur untuk bisa mengisi dua jabatan tersebut. Karena secara normatif dan ideal jabatan Direktur Utama dan Komisaris Utama memang harus

\footnotetext{
${ }^{14}$ Cakaplah. "Akademisi Riau Dorong Tim Konversi BRK Syariah Bekerja dengan Baik”. www.cakaplah.com. (23-04-2019). https://www.cakaplah.com/berita/baca/2019/04/23/akademisiriau-dorong-tim-konversi-brk-syariah-bekerja-dengan-baik\#sthash.BbeDDbzC.dpbs, diakses 23 Juli 2019.

${ }^{15}$ Ibid.

${ }^{16} \mathrm{Ibid}$.
} 
diisi. Kita harus hormati keputusan Gubernur untuk wait and see dulu disitu. Karena beliau pasti punya pemikiran dan pertimbangan sendiri. Saya memandang, publik berharap banyak atas kebijakan pengisian kekosongan jabatan tersebut. Gubernur tentu mempunyai pertimbangan yang matang untuk menampatkan orang di sana, agar konversi berjalan lancar dan Bank Riau Kepri Syariah lebih maju dibandingkan masa konvensional. Dan para stakeholder berharap agar proses pencalonan itu bisa ditetapkan tidak dalam waktu yang lama, agar bank tetap dinilai baik oleh OJK, pungkasnya. $^{17}$

Menurut Ketua LPIP Alaidin Koto, agenda ini bertujuan untuk mengembangkan diskusi-diskusi ilmiah terkait persoalan keumatan dan kebangsaan.

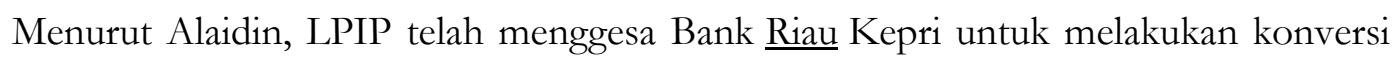
manjadi Syariah. Dalam rangka kemajuan peradaban, kita di Riau sudah menggesa supaya perbankan Riau murni ke syariah supaya kita betul-betul aman. Perbankan syariah itu aman dan menimbulkan ketenangan batin bagi nasabah. Kita mendukung pemerintah agar mewujudak bank syariah secara 100 persen, ujar Alaidin. Alaidin menganalisa, masyarakat banyak ragu dengan sistem ekonomi syariah, juga banyak pejabat pemerintah yang tidak memahaminya. Menurut Alaidin dengan bisnis syariah berarti menyertakan Allah dalam bisnis tersebut. ${ }^{18}$

Menurut salah satu pembicara, Azharuddin M Amin menyebutkan, salah satu kendala mewujudkan perbankan syariah terletak pada sumber daya manusia (SDM). Banyak SDM kurang memahami perbankan syariah, bahkan banyak juga orang-orang yang bekerja di perbankan syariah tidak memiliki latar belakang pendidikan ekonomi syariah. Selain itu menurutnya, masyarakat juga kurang memahami terkait hal tersebut. $^{19}$

Salah satu langkahnya adalah dengan memberikan sosialisai kepada generasi muda, anak-anak sekolah, mahasiswa yang nantinya juga akan menjadi masyarakat agar mereka memahami ekonomi syariah, kata Azhar. Salah satu peserta diskusi Wali

\footnotetext{
${ }^{17}$ Ibid.

${ }^{18}$ Riau Pos. "LPIP Bahas Konversi Bank Riau Kepri ke Syariah”. riaupos.co. (26-03-2019). http://riaupos.co/196672-berita-lpip-bahas-konversi-bank-riau-kepri-ke-syariah.html, diakses 23 Juli 2019.

${ }^{19}$ Ibid.
} 
Saputra menuturkan dalam melakukan konversi harus mempertimbakan persoalan risiko. Menurutnya belum ada satu pun bank syariah yang siap dengan risiko. Sudahkah kita siap kan itu untuk konversi, katanya. ${ }^{20}$

Peserta lainnya, Putra mengungkapkan bahwa paling lambat pada Juli 2023 semua bank syariah wajib menentukan pilihan untuk berpisah dengan bank

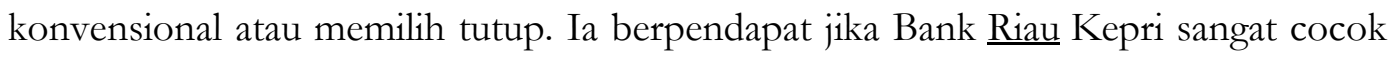
untuk konversi ke syariah karena kultur budaya masyarakat Riau tidak terpisah dari Islam. Kultur kita, Melayu dan tidak terpisah dari Islam, ungkapnya. Putra menambahkan jika hal terpenting dalam konversi adalah SDM dan dorongan pemerintah. Sebeberapa besar kepeduliah pemerintah itulah yang terpenting, ungkapnya. $^{21}$

Sejumlah pelaku usaha sangat mendukung dengan keputusan rapat umu pemeganag saham (RUPS) bank riau kepri di batam pada kamis lalu yang ingin mengkonversi bank milik pemerintah daerah di riau dan kepri ini menjadi syariah. Salah satunya disampaikan oleh Haji Ibnu Mas'ud pemilik perusahaan tour dan travel haji khusus dan umrah muhibbah mulia wisata ini sngat mendukung sekali dnegan rencana konversi itu. Alasannya karena masyaralat riau adalah masyarakat syariah yang sudah lama merindukan ini. ${ }^{22}$

Dan dunia usaha juga sejak lama bergerak kea rah syariah. saatnya BRK ambil momeb ini. Kalau tidak BRK akan ditinggalkan oleh pelaku usaka. Ujarnya kepada media di pekanbru (0/12/2018). Mantan ketua asosiasi pengusaha pariwisata (ASITA) Riau ini mengatakan kesadaran masyarakat tentang riba ini semangkin meningkat. Bahkan banyak pegawai bank konvensional yang mengajukan berhenti dan alih propesi karena sudah tahu mudharat nya usaha riba ini. Untuk riau sendiri, peluang ini sudah lama dinikmati oleh bank swasta ataupun BUMN syariah. mereja

${ }^{20}$ Ibid.

${ }^{21}$ Ibid.

${ }^{22}$ Go Riau. "Pelaku Usha Dukung Konversi Bank Riau Kepri Mendaji Syariah". www.goriau.com. (08-12-2018). https://www.goriau.com/berita/baca/pelaku-usaha-dukungkonversi-bank-riau-kepri-menjadi-syariah.html, diakses 23 Juli 2019. 
menerima limpahan dan eksodus nasabah yang ingin pengelolaann keuanganya dengan syariah, ungkapnya. ${ }^{23}$

Ia pun mewanti wanti kepada para pemangku kebijakan terkait konversi ini untuk serius mewujudkan rencana tersebut. kerena ini sudah menjadi keinginan sebagian besar masyarakat. Saya termasuk sangat mendukung dengan rencana ini, ujar pria yang biasa diapa iwan fatah ini. Apalagi, tambahanya dengan konversi ini, BRK syariah bia menyasar konsumen nasabah dipedesaan yang rata-rata masih terhaga religiusnya. Sehingga perbankan syariah lebih masuk, mengena dan sesuai dengan harapan masyarakat di pekanbaru dan seluruh riau. ${ }^{24}$

\section{PEMBAHASAN}

\section{Gedung Mencakar Langit Menara Dang Merdu Bank Riau Kepri}

Gedung Riau Riau yang megah dan tinggi terletak di Jl. Kota Sudirman Pekanbaru, terdiri dari 15 lantai bernama Menara Dang Merdu Bank Kepri Riau.

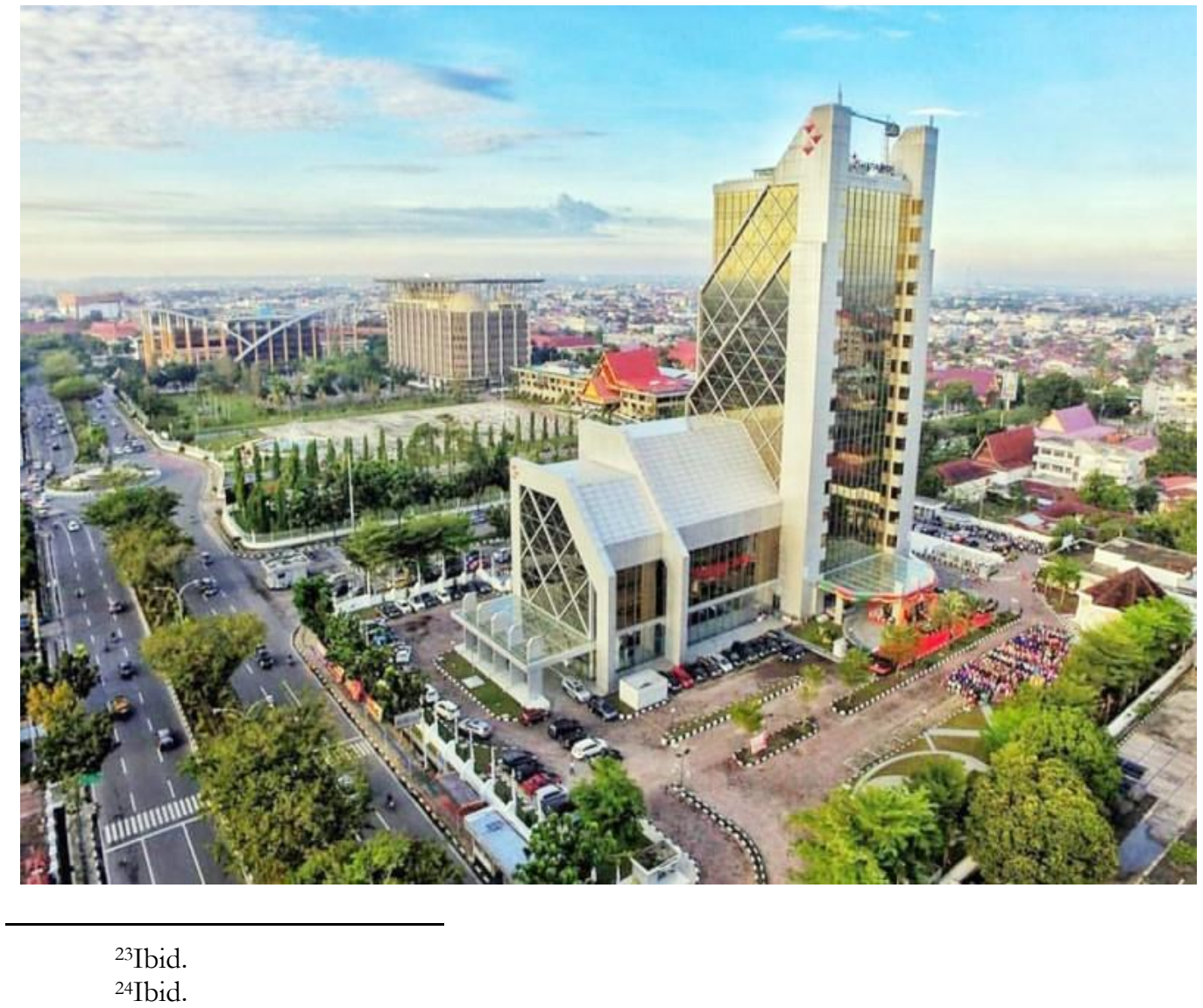




\section{Apasih Bedanya Bank Syariah dengan Bank Konvensional?}

Ada beberapa perbedaan antara bank syariah dan bank konvensional: (1) Semua transaksi bank syariah harus didasarkan pada kontrak yang dibenarkan oleh syariah Islam berdasarkan Alquran dan Hadits Nabi diterjemahkan ke dalam fatwa Dewan Syariah Nasional MUI mengenai perbankan dan jasa. keuangan. Sedangkan bank konvensional beroperasi berdasarkan perjanjian pinjam meminjam uang dengan tujuan menghasilkan laba maksimum (2) Untuk mendapatkan laba (laba) di bank syariah menggunakan perjanjian bagi hasil (mudharabah dan musyarakah), perjanjian jual beli (murabahah, salam, dan istishna), perjanjian sewa (ijarah dan ijarah muntahiya bit tamlik) dan kontrak keagenan (wakalah), sesuai dengan fatwa Dewan Syariah Nasional Dewan Ulama Indonesia (DSN-MUI). Sedangkan bank konvensional mendapat manfaat dari instrumen bunga, terutama kredit bunga dan pendapatan fee lainnya. (3) Setiap bank syariah wajib memiliki Dewan Pengawas Syariah (DPS) yang terdiri dari unsur ulama yang memiliki kompetensi dalam fiqh muamalah dan pengetahuan dalam jasa keuangan. Calon anggota DPS dari bank syariah direkomendasikan oleh Dewan Syariah Nasional MUI dan disetujui oleh Otoritas Jasa Keuangan (OJK). ${ }^{25}$

Dewan Pengawas Syariah memiliki tugas dan tanggung jawab untuk memastikan bahwa setiap produk dan operasi bank syariah sesuai dengan prinsipprinsip Syariah. (4) Di bank syariah, operasi pemerintah secara nasional dan dana produk, pembiayaan dan layanan lainnya selain Peraturan Bank Indonesia / Otoritas Jasa Keuangan juga harus sesuai dengan Fatwa Dewan Syariah Nasional (DSN) MUI, sedangkan di bank konvensional yang mengatur operasi dan dana produk, kredit \& layanan lainnya hanya Peraturan Bank Indonesia / Peraturan Otoritas Jasa Keuangan. (5) Bank syariah didirikan dengan tujuan mendapatkan keuntungan, kesejahteraan para pihak dan kebahagiaan akhirat (falah), sedangkan bank konvensional lebih fokus untuk mendapatkan keuntungan maksimal untuk bank mereka, dibandingkan dengan

${ }^{25}$ Direktur Bid. Syariah PT. Bank Riau Kepri. "Bank Riau Kepri Menjadi Bank Syariah, Suatu Wacana”. www.halloriau.com. (30-06-2016). http://www.halloriau.com/read-ekonomi-81868-2016-06-30-bankriau-kepri-menjadi-bank-syariah-suatu-wacana.html, diakses 21 Juli 2019. 
debitor sendiri tanpa perlu memikirkan dampak manajemen dan orientasi bisnis mereka pada kehidupan setelah mati. ${ }^{26}$

Pada tahap awal pertumbuhan dan untuk mengejar pangsa pasar perbankan nasional saat ini, disedari bahawa praktik bank Islam di Indonesia tidak berjalan dengan sempurna menurut Syariah tetapi proses penambahbaikan terus dilakukan dengan tujuan agar di masa depan operasi bank-bank Islam dapat berjalan sesuai Syariah Islam dengan merujuk petunjuk Al-Quran dan hadis nabi. ${ }^{27}$

\section{Pilihan Yang Tepat Bagi Bank Riau Kepri Konversi atau Spin Off}

Spin off bermaksud berpisah dari induk, yang bermaksud bahawa sebenarnya akan ada 2 bank entiti, iaitu bank induk (bank konvensional) dan bank subsidiari (bank Islam). Pola putaran model ini dipraktikkan oleh BJB Bank ketika menjalankan pemisahan unit perniagaan syariahnya pada tahun 2010, tetapi bank-bank subsidiarinya tidak berkembang dengan baik, terutamanya kerana masalah pendanaan dan modal perniagaan. Mengubah makna semua aktiviti perniagaan dan pergeseran portfolio perniagaan secara total dari bank konvensional menjadi bank Islam, corak ini akan dilaksanakan oleh Bank Aceh dan Bank Nusa Tenggara Barat. ${ }^{28}$

PT Bank Riau Kepri optimis bahawa rancangan untuk memisahkan atau memisahkan unit perniagaan syariah akan berjalan lancar, sejajar dengan prestasi positif UUS sepanjang tahun 2017. Tahun lalu, Bank Riau Kepri UUS menyumbangkan keuntungan Rp31.32 miliar, dengan aset Rp2.32 triliun. "Kami percaya bahawa prestasi UUS akan terus berkembang setelah putaran. Kami telah melakukan kajian, dan semua indikator menunjukkan angka yang baik, "kata Pengarah Urusan Bank Riau Kepulauan Riau Irvandi Gustari kepada Bisnis pada hari Ahad $(18 / 2){ }^{29}$

Irvandi mengatakan bahawa pejabatnya mensasarkan Bank Kepulauan Riau Riau untuk memperoleh keuntungan Rp69,04 triliun pada tahun 2020. Sasarannya

\footnotetext{
${ }^{26}$ Ibid.

${ }^{27}$ Ibid.

28Ibid.

${ }^{29}$ Perniagaan. Com, 2018.
} 
akan diimbangi oleh pertumbuhan aset menjadi Rp5,4 triliun pada tahun yang sama dari sebelumnya Rp 2,32 triliun pada tahun 2017. Potensi besar perbankan Islam di Riau dan Kepulauan Riau, syarikat tersebut menetapkan sasarannya. Sehingga September 2017, pangsa pasar dana pihak ketiga Bank Riau Riau Kepulauan UUS di kedua provinsi tersebut mencapai $20.7 \% .^{30}$

Pada masa ini UUS Bank Riau Kepri juga memiliki jumlah jemaah haji ketiga terbesar dengan 31,473 pelanggan. Tahun lalu terdapat 36.15 juta akaun dan baki simpanan haji-umrah mencapai Rp67.56 bilion, katanya. Bank Riau Kepri juga akan bergantung pada kedekatan budaya Melayu yang dekat dengan Kepulauan Riau sebagai tempat penjualannya sendiri. Diharapkan Bank Kepulauan Riau Syariah Riau dapat mengembangkan dan memimpin perbankan Islam di kedua provinsi tersebut. ${ }^{31}$

Irvandi juga menekankan bahawa pemutusan UUS Bank Riau Kepri akan menjadi proyek percontohan untuk bank pembangunan daerah yang dimiliki oleh kedua provinsi tersebut. Lebih-lebih lagi, pada masa ini banyak provinsi baru mempunyai cita-cita untuk memiliki bank mereka sendiri. Sebelumnya, Mesyuarat Agung Luar Biasa Pemegang Saham Bank Riau Kepri bersetuju untuk memisahkan Unit Perniagaan Syariahnya untuk menjadi Bank Kepulauan Riau Kepulauan Riau. Bank ini akan berpusat di Tanjung Pinang, Kepulauan Riau. Bank Riau Kepri saat ini sedang meminta izin kepada Otoritas Perkhidmatan Keuangan (OJK) untuk disetujui, dan proses penyediaannya dilakukan sesuai dengan peraturan putus-putus dari pihak berwenang. ${ }^{32}$

Bank Riau Kepri juga menyiapkan Rp500 miliar sebagai modal awal untuk penubuhan Riau Syariah Riau Bank. "Awalnya semua modal awal kami dan jika ia berjalan, kami akan memberikannya kembali kepada pemerintah daerah," katanya. Pelaburan modal penuh dari tunai Bank Riau Kepri dilakukan agar proses pembentukan anak syarikat tidak terhambat. Sebabnya ialah terdapat proses

${ }^{30} \mathrm{Ibid}$

${ }^{31}$ Ibid.

${ }^{32}$ Bisnis Com. "Spin Off Unit Usaha Syariah: Bank Riau Kepri Optimistis Mulus". kalimantan.bisnis.com. (19-02-2018). https://kalimantan.bisnis.com/read/20180219/445/739954/spin-off-unit-usaha-syariah-bank-riaukepri-optimistis-mulus, diakses 25 Juli 2019. 
pentadbiran yang memerlukan masa sekiranya penyertaan ekuiti dilakukan oleh pemerintah daerah. ${ }^{33}$

Yusri, Pemangku Ketua OJK Riau, mengatakan Kepulauan Riau dan Riau memiliki potensi ekonomi Islam yang cukup besar. Itu juga membuka peluang bagi industri perbankan Islam untuk mengusahakannya secara optimum. Ada banyak potensi yang dapat diusahakan oleh bank-bank Islam, mulai dari sektor UMKM hingga berpartisipasi dalam berbagai proyek infrastruktur, dan tentu saja sektor pelancongan yang sedang dikembangkan secara intensif oleh pemerintah, katanya. (Lili Sunardi). ${ }^{34}$

\section{Bank Riau Kepri Syariah Merupakan Unit Usaha Syariah Bank Riau Kepri}

Bank Riau Kepri yang ditubuhkan 50 tahun yang lalu, sebenarnya sudah memiliki Unit Usaha Syariah sejak 22 Julai 2004 (12 tahun). Unit Perniagaan Syariah (UUS) bermaksud satu unit perniagaan yang perniagaannya masih digabungkan dengan perniagaan konvensional yang berdasarkan Undang-undang Perbankan Syariah No. 21 Tahun 2008 dan Peraturan Bank Indonesia, harus terpisah dari bisnis induk selambat-lambatnya tahun 2023 dengan syarat-syarat tertentu, jika tidak dapat direalisasikan maka akibat dari perniagaan syariah harus dibubarkan atau ditutup. Berikut data jaringan Kantor Kepulauan Riau Riau: Markas Unit Perniagaan Syariah di Pekanbaru, 2 pejabat cawangan syariah (Pekanbaru dan Tanjung Pinang), 6 pejabat cabang syariah (Tembilahan, Duri, Batam, Taluk Kuantan, Panam dan Tanjung Balai Karimun), 1 pejabat tunai syariah di Kementerian Agama Kab. Siak dan 52 unit perkhidmatan syariah di seluruh jaringan kantor cabang dan cabang Bank Riau Kepri. Data kewangan Bank Riau Kepri Syariah juga menunjukkan perkembangan yang baik. Di mana aset Bank Riau Kepri Syariah dalam 2 tahun terakhir telah melebihi angka di atas Rp 1 triliun, Dana Pihak Ketiga di atas Rp 800 miliar dan Pembiayaan di atas Rp 950 miliar. $^{35}$

${ }^{33}$ Perniagaan. Com, 2018.

${ }^{34}$ Ibid.

${ }^{35}$ Direktur Bid. Syariah PT. Bank Riau Kepri. "Bank Riau Kepri Menjadi Bank Syariah, Suatu Wacana”. www.halloriau.com. (30-06-2016). http://www.halloriau.com/read-ekonomi-81868-2016-06-30-bankriau-kepri-menjadi-bank-syariah-suatu-wacana.html, diakses 21 Juli 2019. 
Pertumbuhan Bank Riau Kepri Syariah sejajar dengan pertumbuhan Bank Riau Kepri secara keseluruhan di mana aset Bank Riau Kepri selalu di atas Rp20 triliun, DPK di atas Rp15 triliun dan pinjaman di atas Rp14,5 triliun. Maknanya ketika memilih spin off akan terbentuk 2 bank entiti, tetapi bank-bank Islam akan berkembang dengan sangat perlahan dan dikhuatiri ia akan dikendalikan oleh persaingan yang sengit. Namun, jika pilihan penukaran dipilih, asetnya akan menjadi besar sehingga tidak mustahil Bank Riau Kepri Syariah akan menjadi salah satu daripada 10 bank syariah terbesar di Indonesia. ${ }^{36}$

\section{Mekanisme Konversi Menjadi Bank Syariah Riau Kepri}

Mekanisme untuk menukar ke bank Islam tentunya tidak begitu sukar. Perkara yang paling penting adalah adanya niat dan kehendak yang kuat di mana keputusan dibuat oleh pemegang saham pengendali, dalam hal ini Pemerintah Provinsi Riau yang disetujui oleh DPRD Provinsi, dan kemudian dibawa ke Mesyuarat Agung Pemegang Saham untuk diputuskan dalam Mesyuarat Agung Pemegang Saham (GMS LB). maka proses tersebut dilakukan dengan meminta persetujuan OJK dan diharapkan OJK tentu saja memberikan kelulusan kerana OJK juga mempunyai misi untuk mengembangkan bank-bank Islam di Indonesia, mengikuti ketinggalan kami di mana dari segi aset bank-bank Islam baru berada pada kedudukan 5\% berbanding aset bank negara. Cuba bandingkan dengan negara jiran, Malaysia, di mana bahagian pasaran industri bank Islam telah mencapai 20\% daripada jumlah keseluruhan industri perbankan nasional di Malaysia. ${ }^{37}$

Sedangkan dari sisi teknis operasi bank, hanya memperbaiki sistem teknologi informasi dan kemudian menetapkan perjanjian pembiayaan dan pembiayaan yang harus sesuai dengan prinsip syariah dan ini dapat dilakukan dengan penanda aras kepada Bank Aceh, yang saat ini sedang dalam proses reformasi. Proses ini juga dapat menggunakan bantuan khidmat perundingan yang tentunya memerlukan sedikit kerja keras di semua bidang, tetapi ini bukan halangan yang signifikan dan dengan semangat kebersamaan, insya Allah dapat dilaksanakan. Terutama bagi pihak

\section{Ibid.}

${ }^{37}$ Ibid. 
pengurusan, dalam praktiknya di Bank Aceh tidak ada yang berubah, semua tingkat Dewan Komisaris, Pengarah, Pegawai Eksekutif dan semua pegawai tetap menjadi pekerja yang sama (ada) tanpa ada yang berubah, cuma budaya kerja syarikat mengutamakan ciri dan ciri budaya Islam universal. ${ }^{38}$

\section{Bumi Lancang Kuning Melayu Riau-Kepri Negeri Islami}

Sejarah menunjukkan semua kerajaan Melayu moden di Kepulauan Riau dan Kepulauan Riau seperti Kerajaan Riau Lingga, Kesultanan Siak, Kerajaan Inderagiri dan Kerajaan Tambusai dan kerajaan lain di Kepulauan Riau dan Kepulauan Riau identik dengan Islam, kehidupan sehari-hari, budaya yang sangat Islamik, sehingga ada Nasihat adat Melayu dari Raja Ali Haji yang sangat terkenal dengan "Gurindam Dua Belas" yang pada dasarnya merupakan pesanan dan nasihat mengenai 4 perkara: Syariat, tariqa, intipati dan hikmah yang bersumber dari kitab suci al-Quran dan hadis Nabi SAW yang menjadi pedoman hidup untuk terus bertahan di dunia dan akhirat. ${ }^{39}$

Sharak adalah kebiasaan, bersyukur atas nikmat dari kitab Allah. Makna pepatah Melayu adalah bahawa adat yang disokong oleh undang-undang Islam mesti berdasarkan Al-Quran dan hadis. Ungkapan ini umumnya digemakan sebagai falsafah hidup masyarakat Melayu di Sumatera timur. Itulah wilayah yang pernah dipengaruhi oleh Kesultanan Melayu yang mula berkembang pada abad ke-13. Salah satu warisan dari kegemilangan Kesultanan Melayu adalah Riau. Jadi, jangan terkejut jika perjalanan ke Riau selalu melihat orang-orang Melayu lincah ke masjid, tidak mahu mengabaikan kewajiban solat, dan membaca Al-Quran. Bagi orang Melayu, baik "Tanah Riau" dan "Kepulauan Riau", ibadah adalah seperti nafas kehidupan. ${ }^{40}$

Mereka tidak akan melanggar tanggungjawab mereka dalam Islam. Sekiranya melanggarnya, apatah lagi meninggalkan Islam, alias murtad, ia tidak lagi dianggap Melayu. Walau bagaimanapun, penduduk di sini sangat terbuka untuk pendatang baru yang mencari rezeki. Seperti watak khas masyarakat Melayu yang ramah menerima

${ }^{38}$ Ibid.

${ }^{39}$ Ibid.

${ }^{40}$ Medcom. "Riau, Budaya Islam, dan Tanah Air Melayu". www.medcom.id. (27-07-2017). https://www.medcom.id/telusur/medcom-files/8KyGZrEb-riau-budaya-islam-dan-tanah-air-melayu, diakses 23 Juli 2019. 
tetamu. Pertumbuhan ekonomi Riau yang pesat memang dapat disamakan dengan "gula" yang mengundang "semut" datang dari berbagai daerah di Indonesia. Tidak dapat dielakkan, arus migrasi pencari kerja yang cepat di sini telah mendorong Riau menjadi salah satu provinsi dengan tingkat pertumbuhan penduduk tertinggi di Indonesia. Paling tidak, fenomena ini berlaku sejak 30 tahun kebelakangan ini. Demografi Riau sangat pelbagai, tidak sukar untuk mencari kumpulan etnik lain yang tinggal di Bumi Lancang Kuning. Namun, seperti kata pepatah di mana bumi diinjakinjak di langit, para pendatang di Riau masih harus menyesuaikan diri dengan norma sosio-budaya Melayu. ${ }^{41}$

Menurut Ketua Persatuan Sejarah Indonesia Riau (MSI), Isjoni, tidak sedikit masyarakat suku selain Melayu berkembang pesat di Riau, terutama di kawasan bandar. Sebilangan besar mereka juga berkongsi nilai-nilai Melayu di Riau. Sekarang, ini unik di Riau, orang dari pelbagai etnik akan dianggap sebagai orang Melayu selagi dia beragama Islam. Contohnya, jike anda mempunyai etnik Batak dan Muslim, maka anda dipanggil Melayu-Batak. Begitu juga, orang Sunda yang beragama Islam disebut Melayu-Sunda, orang Bugis yang beragama Islam disebut Melayu-Bugis, dan sebagainya. Jadi, di sini banyak orang luar menjadi orang Melayu. Begitu banyak persatuan seperti Melayu-Minang, Melayu-Jawa, dan pelbagai, semuanya dapat hak yang sama, "kata Isjoni dalam perbualan dengan medcom.id di Universiti FKIP Riau, Pekanbaru, Khamis, 15 Jun $2017^{42}$

Gabenor Riau Arsyadjuliandi Rachman komited untuk menjadikan kawasan yang dipimpinnya sebagai pusat kebudayaan Melayu di wilayah Asia Tenggara. Visi ini telah diatur secara eksplisit dalam Peraturan Daerah (Perda) Provinsi Riau Nomor 36 Tabun 2001. Arsyadjuliandi menyatakan bahwa semua institusi, institusi dan masyarakat di Provinsi Riau diharuskan melaksanakan visi dan misi ini, untuk mencapai Riau sebagai pusat budaya Melayu di Asia Tenggara. Menurutnya, ini penting untuk mendukung potensi pelancongan, salab satunya adalah pelancongan budaya. "Budaya Melayu adalab keunggulan Riau," kata Arsyadjuliandi di Pekanbaru, Khamis 5 Jun 2017 (Medcom, 2017).

Dia menjelaskan, destinasi pelancongan budaya termasuk, seperti Sungai Siak, Kampar, Indragiri, dan Rokan. Kemudian Kuil Muara Takus dan Istana Siak. Dengan membawa tagline:

${ }^{41}$ Ibid.

${ }^{42}$ Ibid. 
Riau The Homeland Of Malay, ada nilai pelestarian budaya yang dapat diambil dari laman web ini. Potensi pelancongan budaya Riau sangat besar, tambahnya. Menurut Isjoni, langkah Pemerintah Provinsi Riau sesuai dan harus disokong. Kerana, hingga kini Riau masib terus menghidupkan budaya Melayu. "Riau adalah tanah air Melayu," kata Profesor dalam pendidikan di Universiti Riau. ${ }^{43}$

Orang Melayu adalah salah satu kumpulan etnik Austronesia yang mendiami Semenanjung Tanah Melayu, Sumatera Timur, Thailand Selatan, Pantai Selatan Myanmar, Pulau Singapura, Kalimantan (Kalimantan Barat, Sarawak, Sabah, dan Brunei) dan Filipina Selatan. Secara kolektif, wilayah ini disebut Dunia Melayu. Selain pulau-pulau, bahasa Melayu juga terdapat di Sri Lanka, Kepulauan Cocos (Australia), dan di Afrika, seperti Madagascar dan Afrika Selatan. Istilah Melayu berasal dari Kerajaan Melayu di tebing sungai Batang Hari, Jambi, yang pada waktu itu memasuki wilayah kerajaan Sriwijaya. Dari masa ke masa, penggunaan istilah bahasa Melayu berkembang di luar Sumatera setelah pengembangan kuasa Srivijaya. ${ }^{44}$

Isjoni menjelaskan, asal-usul orang Melayu dijangka datang ke pulau-pulau pada 1500-500 SM (SM). Orang Melayu datang dalam dua gelombang. Gelombang pertama dipanggil Proto Melayu (Melayu Lama). Mereka berasal dari Yunnan (China) dan kepulauan Taiwan. Orang Melayu Proto memasuki Nusantara melalui dua laluan; Barat dan Timur. Laluan barat melalui Semenanjung Tanah Melayu ke Sumatera dan merebak ke pelbagai wilayah di pulau-pulau. Sementara itu, laluan timur melalui Kepulauan Filipina ke Sulawesi dan merebak ke berbagai bahagian pulau. Orang Melayu Proto membawa budaya neolitik, tetapi peradaban mereka lebih maju daripada manusia kuno yang terdapat di Indonesia. ${ }^{45}$

Pada tahun 500 SM, gelombang Deutro Malay (Young Young) mula memasuki pulau-pulau secara beransur-ansur. Kedatangan Deutro yang layu membuat orang Melayu Proto berkeras dan pergi ke timur. Diduga, proto Melayu masih tinggal di Indonesia dan membentuk kumpulan etnik mereka sendiri seperti suku Dayak, Toraja, Mentawai, Nias, dan Papua. Di Sumatera, orang keturunan Melayu Proto masih dapat dijumpai. Mereka dikenal oleh suku Sakai di Siak dan suku

${ }^{43}$ Ibid.

${ }^{44}$ Ibid.

${ }^{45}$ Ibid. 
Kubu di Palembang. Isjoni mengatakan bahawa tamadun Melayu Deutro selangkah lebih maju daripada orang Melayu Proto. Mereka sudah pandai membuat objek gangsa dan besi seperti kapak corong, nekara, dan kapal. Deutro Melayu berasal dari Indochina (Dong Son, Vietnam). ${ }^{46}$

Lama kelamaan, Deutro Melayu merebak ke pelbagai wilayah di Nusantara. Mereka juga membentuk kumpulan atau suku yang terpisah seperti Melayu, Jawa, Sunda, Bugis, Minang, dan lain-lain. Orang Minang, Aceh, Jawa dan suku lain, berasal dari nenek moyang yang sama. Ini dapat dilihat dari kesamaan bahasa yang dimiliki oleh setiap suku, "jelasnya. Kemudian, istilah bahasa Melayu telah menyempitkan maknanya. Dalam konteks semasa, orang Melayu dianggap orang yang bertutur dalam bahasa Melayu dan beragama Islam. Ini tidak dapat dipisahkan dari kegemilangan Kesultanan Melayu di Alam Melayu Fail sejarah Melayu di Perpustakaan Masjid Besar Sultan Riau, Pulau Penyengat, Kepulauan Riau. (MI / Immanuel Antonius). ${ }^{47}$

Kerajaan Melayu-Riau adalah warisan Kerajaan Sriwijaya (683-1025 Masihi). Keberadaan situs Kuil Muara Takus di Kampar, dikatakan sebagai warisan kerajaan Sriwijaya di Riau. Srivijaya adalah kerajaan Melayu kuno yang menganut agama Hindu dan Buddha. Bahasa Melayu kuno dan Sanskrit digunakan di persekitaran kerajaan. Wilayah Srivijaya cukup besar, membentang dari Sumatera hingga Jawa Barat, sedikit di Jawa Tengah, Semenanjung Tanah Melayu, Thailand Selatan dan Kemboja. Sekitar abad ke-10, kemenangan Srivijaya mulai memudar. Tepatnya, ketika Srivijaya diserang oleh sebuah negara di India. Pada tahun 1025, Dinasti Chola, sebuah negara yang berpusat di Coromandel (pantai selatan India) yang dipimpin oleh Rajendra Chola I, melancarkan serangan dan berjaya melemahkan dominasi Srivijaya di Kepulauan. Kekuatan Sriwijaya berakhir. ${ }^{48}$

Kejatuhan Srivijaya meninggalkan warisan mandala yang ingin berdaulat. Salah satunya, Kerajaan Melayu yang bermula dari Kerajaan Bintan-Tumasik pada abad ke-12, kemudian memasuki zaman Melayu-Riau pada Kesultanan Melaka pada abad ke-14 hingga ke-15, Kesultanan Johor-Kampar pada abad ke-16-17, dan

${ }^{48}$ Ibid. 
berakhir pada Kesultanan. Riau-Lingga abad 18-19. Istana Asherayah Al-Hasyimiyah (Istana Siak Sri Indrapura) Kesultanan Siak Sri Inderapura, Siak, Riau. (ANTARA / Ismar Patrizki). ${ }^{49}$

Provinsi Riau diberi makan oleh empat sungai utama yang berperanan menyebarkan Islam. Empat sungai; Sungai Siak panjangnya 300 kilometer dengan kedalaman 8-12 meter, Sungai Rokan sepanjang 400 kilometer dengan kedalaman 6-8 meter. Sungai Kampar panjangnya 400 kilometer dengan kedalaman 6 meter, dan Sungai Indragiri sepanjang 500 kilometer dengan kedalaman 6-8 meter. Keempat sungai tersebut berasal dari dataran tinggi Bukit Barisan dan kosong ke Selat Melaka dan Laut China Selatan. Gelombang dipengaruhi oleh gelombang Laut China Selatan. Kerana lokasi Riau berada di daratan rendah, penggunaan kapal untuk pengangkutan air sebagian besar dilakukan oleh masyarakat. ${ }^{50}$

Lebih-lebih lagi, pusat bandar kerajaan Melayu di Riau tidak jauh dari tebing sungai. Pedagang dari India, China dan Arab-Parsi dikatakan berlayar untuk menelusuri empat sungai di Riau untuk berniaga. Desa Kuntu di Kampar adalah daerah di Tanah Besar Riau yang pertama kali dikunjungi oleh para pedagang. Ini kerana kawasan lembah sungai Kampar Kiri terkenal sebagai kawasan penghasil lada terpenting di dunia pada abad ke-6 hingga 13. Syeikh Burhanuddin dikenali oleh orang Arab yang pertama kali menyebarkan agama Islam di Kuntu-Kapar. Dia dilahirkan di Mekah pada tahun 1111 dan meninggal di Kuntu pada tahun 1191. Sheikh Burhanuddin menyebarkan agama Islam kepada masyarakat Melayu di Riau selama 20 tahun. Pada waktu itu, masyarakat Melayu Riau masih menganut agama Hindu dan Buddha yang merupakan peninggalan kerajaan Sriwijaya. ${ }^{51}$

Dari Kuntu, Islam dianggap menyebar ke Rokan pada tahun 1349. Islam dibawa ke Rokan oleh buronan dari Kuntu. Pada waktu itu, Kuntu diserang oleh pasukan Adityawarman dari Dharmasraya, bekas kota Kerajaan Sriwijaya. Bukan hanya itu, pelarian Kuntu juga merebak ke Kuantan dan Indragiri. Mereka menetap 
di wilayah itu sambil menyebarkan Islam. Sehingga kini, warisan budaya kerajaan Melayu-Islam masih terpelihara di Riau. ${ }^{52}$

\section{Perbankan Syariah dan Toleransi Non-Muslim}

Dalam praktiknya, bank-bank Islam berkembang di beberapa negara maju seperti di UK, Perancis dan bahkan di Asia Tenggara. Tepat di Singapura, bank-bank Islam jauh lebih maju daripada di Indonesia dan menurut sebilangan rakan penulis di beberapa bank Islam nasional banyak pelanggan (baik pembiayaan dan pembiayaan) berasal dari kalangan bukan Islam dan mereka adalah pelanggan yang baik dan dapat memahami produk bank Islam dengan baik kerana dilaksanakan dengan prinsip yang lebih adil..$^{53}$

Beberapa bank Islam swasta nasional juga dimiliki oleh orang bukan Islam, misalnya Bank Syariah BCA, Bank Syariah Panin, Bank Syariah Victoria. Ini bererti bahawa setiap orang dapat bertransaksi, memanfaatkan dan mengurus bank Islam selagi mereka mengikuti prinsip dan prosedur bermuamalah sesuai dengan hukum syarak. Inilah salah satu bukti Islam adalah rahmatan lil alamin (undang-undang Islam adalah hadiah dan berkat bagi semua manusia dan semua alam). ${ }^{54}$

\section{KESIMPULAN}

Penjelasan di atas dapat disimpulkan oleh penulis bahwa: Sekiranya Bank Kepulauan Riau Riau mempunyai keinginan untuk ditukar menjadi bank Islam dapat dilaksanakan, tanpa ada peraturan yang dilanggar, hanya proses dan mekanisme yang harus diikuti sesuai dengan prosedur dan peraturan yang ditetapkan oleh Pihak Berkuasa. Bank Riau Kepri ditukar menjadi Bank Syariah dari segi aset memiliki peluang untuk menjadi salah satu dari 10 bank syariah terbesar di Indonesia, bandingkan jika tetap di bank konvensional sekurang-kurangnya hanya dalam urutan 80 dari 118 bank di Indonesia, akan menjadi semakin sukar bersaing di tengah-tengah pasaran ekonomi ASEAN dan serangan bank-bank global yang bergegas memasuki

${ }^{52}$ Ibid.

53Pengarah Bidang Syariah. PT. BRK, 2016

${ }^{54}$ Ibid. 
pasaran Indonesia. Kepulauan Riau Melayu dan Riau identik dengan Islam, walaupun mereka telah lama tinggal sebagai jiran dengan pelbagai suku, tetapi undang-undang yang selalu digunakan adalah undang-undang Islam yang bergantung kepada Kitab Allah dan Sunnah Nabi dan semua komponen masyarakat dapat hidup dalam kedamaian dan kedamaian. Bank Riau Kepri diubah menjadi bank Islam, ia akan menghilangkan syak (ragu-ragu) di hati para pekerja yang bekerja di bank konvensional, terutama dengan adanya MUI Fatwa No. 1 tahun 2004 yang menyatakan bahawa kepentingan bank adalah antara riba yang dilarang, di mana hampir 99.99\% pekerja Bank Riau Kepri adalah beragama Islam.

\section{DAFTAR PUSTAKA}

Bisnis Com. "Bank Riau Kepri Segera Konversi Jadi Bank Syariah”. finansial.bisnis.com. (21-032019). https://finansial.bisnis.com/read/20190321/90/902583/bank-riaukepri-segera-konversi-jadi-bank-syariah, diakses 21 Juli 2019.

Bisnis Com. "Spin Off Unit Usaha Syariah: Bank Riau Kepri Optimistis Mulus". kalimantan.bisnis.com. (19-02-2018). https://kalimantan.bisnis.com/read/20180219/445/739954/spin-off-unitusaha-syariah-bank-riau-kepri-optimistis-mulus, diakses 25 Juli 2019.

Cakaplah. "Akademisi Riau Dorong Tim Konversi BRK Syariah Bekerja dengan Baik”. www.cakaplah.com. (23-04-2019).

https://www.cakaplah.com/berita/baca/2019/04/23/akademisi-riaudorong-tim-konversi-brk-syariah-bekerja-denganbaik\#sthash.BbeDDbzC.dpbs, diakses 23 Juli 2019.

Direktur Bid. Syariah PT. Bank Riau Kepri. "Bank Riau Kepri Menjadi Bank Syariah, Suatu Wacana”. www.halloriau.com. (30-06-2016). http://www.halloriau.com/readekonomi-81868-2016-06-30-bank-riau-kepri-menjadi-bank-syariah-suatuwacana.html, diakses 21 Juli 2019.

Direktur Bid. Syariah PT. Bank Riau Kepri. "Bank Riau Kepri Menjadi Bank Syariah, Suatu Wacana”. www.halloriau.com. (30-06-2016). http://www.halloriau.com/readekonomi-81868-2016-06-30-bank-riau-kepri-menjadi-bank-syariah-suatuwacana.html, diakses 21 Juli 2019.

Go Riau. "Pelaku Usha Dukung Konversi Bank Riau Kepri Mendaji Syariah". www.goriau.com.

(08-12-2018). https:/ /www.goriau.com/berita/baca/pelaku-usaha-dukung-konversi-bankriau-kepri-menjadi-syariah.html, diakses 23 Juli 2019. 
Medcom. "Riau, Budaya Islam, dan Tanah Air Melayu". www.medcom.id. (27-072017). https://www.medcom.id/telusur/medcom-files/8KyGZrEb-riaubudaya-islam-dan-tanah-air-melayu, diakses 23 Juli 2019.

Radio Republik Indonesia. "OJK Awasi Ketat Proses Konversi BRK Menjadi Bank Syariab". rri.co.id.

http://rri.co.id/pekanbaru/post/berita/697519/ekonomilojk_awasi_ketat_proses_ko nversi_brk_menjadi_bank_syariah.btml, diakses 23 Juli 2019.

Republika. "Bank Riau Kepri Ingin Konversi ke Syariah, Ini Saran OJK". m.republika.co.id. (26-01-2019). https://m.republika.co.id/berita/ekonomi/syariahekonomi/19/01/26/plxfau383-bank-riau-kepri-ingin-konversi-ke-syariah-inisaran-ojk, diakses 21 Juli 2019.

Riau Pos. "LPIP Bahas Konversi Bank Riau Kepri ke Syariah". riaupos.co. (26-032019). http://riaupos.co/196672-berita-lpip-bahas-konversi-bank-riau-keprike-syariah.html, diakses 23 Juli 2019. 